\title{
PERCEPÇÕES A RESPEITO DA IMPLANTAÇÃO DA GESTÃO POR PROCESSOS EM UMA ÁREA DE UMA EMPRESA INTEGRADA DE ENERGIA
}

\section{PERCEPTIONS ABOUT THE IMPLEMENTATION OF BUSINESS MANAGEMENT PROCESSES IN AN AREA OF AN INTEGRATED ENERGY COMPANY}

\author{
Aziz Khazzah el Warrak ${ }^{1}$; José Rodrigues de Farias Filho ${ }^{2}$ \\ ${ }^{1}$ Universidade Federal Fluminense - UFF - Rio de Janeiro - Brasil \\ azizkwarrak@yahoo.com.br \\ ${ }^{2}$ Universidade Federal Fluminense - UFF - Rio de Janeiro - Brasil \\ fariasfilho@gmail.com
}

\begin{abstract}
Resumo
O presente estudo tem por objetivo identificar as percepções de profissionais envolvidos na implementação da gestão por processos acerca de aspectos envolvidos em sua aplicação. Para tanto, foi necessário estudar os conceitos relacionados à gestão por processo. A metodologia utilizada considera uma pesquisa de natureza aplicada, pois pretende contribuir de maneira prática para solucionar um problema concreto. A abordagem é qualitativa, pois a interpretação dos fenômenos é imprescindivel para o alcance dos objetivos propostos. Quanto aos objetivos, este estudo é classificado como exploratório, uma vez que busca conhecer melhor o tema abordado. E como método de pesquisa adotou-se um estudo de caso. Os dados foram coletados através de entrevistas de forma espontânea e analisados através do método de análise de conteúdo qualitativa na forma de sumarização. Os resultados obtidos nesta dissertação foram as percepções dos entrevistados a respeito das vantagens, pontos positivos, desvantagens, pontos negativos, facilitadores, dificultadores e fatores críticos de sucesso na implantação da gestão por processos.
\end{abstract}

Palavras-chave: gestão por processos; processos; qualidade total.

\section{Introdução}

As organizações são administradas segundo a visão das funções empresariais, sendo rotuladas como "baseada em funções". Essa forma de funcionamento é muito danosa para os processos que, tendo necessidade de fluir transversalmente entre as diversas unidades da organização que executam partes da atividade, passam a ter barreiras insuperáveis de trocas de informações, produtos, energia e comunicação, em face das restrições impostas pelo efeito silo da abordagem funcional (MARANHÃO; MACIEIRA, 2004).

Pesquisa realizada por Rummler e Brache (1994) confirma que a maioria dos executivos descreve suas organizações pelos departamentos que a compõem. Essa visão permanece até os dias 
de hoje, conforme colocado por Harmon (2007), que caracteriza as organizações deste tipo, como “organizações de estrutura tradicional".

A presente pesquisa identifica as percepções a respeito da Gestão por Processos, sob o ponto de vista de profissionais de uma área de uma empresa de energia em que esse modelo foi aplicado.

O Quadro 1 descreve de forma clara a contextualização e o problema atacado na pesquisa.

Quadro 1 - Contextualização e problema da pesquisa

\begin{tabular}{|c|c|}
\hline Contextualização & Problema \\
\hline $\begin{array}{c}\text { As empresas são voltadas para as funções e não para } \\
\text { processos. }\end{array}$ & \multirow{3}{*}{$\begin{array}{l}\text { Dificuldade de identificar junto a profissionais que } \\
\text { contribuíram na implementação da gestão por } \\
\text { processos, as vantagens, desvantagens, } \\
\text { facilitadores e dificultadores desse modelo de } \\
\text { Gestão por Processos }\end{array}$} \\
\hline $\begin{array}{l}\text { Cada vez mais as organizações estão buscando uma } \\
\text { gestão com foco nos processos. }\end{array}$ & \\
\hline $\begin{array}{l}\text { Os profissionais descrevem suas organizações pelos } \\
\text { departamentos que a compõem. }\end{array}$ & \\
\hline
\end{tabular}

Fonte: Autoria própria (2013)

A partir do problema mencionado acima, definiu-se o objetivo da pesquisa como identificar as percepções de profissionais envolvidos na implementação da gestão por processos acerca de aspectos envolvidos em sua aplicação.

Para tanto, é importante desenvolver o conceito-chave "Gestão por Processos" que fundamenta a pesquisa.

\section{Referencial teórico}

\subsection{Histórico de processos}

O tema "processos" não pode ser considerado como algo novo para as empresas, assim como, o tema "gestão". Provavelmente, as primeiras organizações que surgiram durante a Revolução Industrial possuíam alguma forma de gerir seus negócios, mesmo que de forma primitiva. Smith (2007) coloca que os conceitos de processos não são recentes e as ferramentas e técnicas de análise e melhoria têm sido aplicadas há muitas décadas. A evolução da gestão passa pelo modelo de Taylor na década de 1920, considerado por Smith e Fingar (2003) como a primeira onda ou fase evolutiva da utilização da visão de processos nas organizações. Nesse modelo, havia processos não automatizados implícitos nas práticas de trabalho.

No início da década de 1990, o tema "processos" passa a ser discutido com mais frequência pelas organizações. Nesse momento, surge o que Smith e Fingar (2003) chamam de segunda onda, a Reengenharia de Processos. Esse conceito surgiu inicialmente em 1990 e tem como principais autores Michael Hammer, James Champy, Thomas Davenport, James Short e James Harrington. A reengenharia de processos prega a desconstrução completa dos processos existentes e a criação de processos novos completamente diferentes dos que já existiam. 
A chamada terceira onda teve início no final da década de 1990 e início dos anos 2000 e consiste na atual fase da Gestão por Processos. Os autores mais influentes nessa fase são Hammer , Harmon, Rosemann, Jeston e Nelis, Spanyi e os próprios Smith e Fingar. A terceira onda aproveita todos os benefícios advindos das metodologias, ferramentas e tecnologias dos ciclos anteriores para implantar, gerenciar e melhorar processos de maneira mais madura (SOUSA NETO; MEDEIROS JUNIOR, 2008). Desta forma, a visão mais recente da Gestão por Processos trata os processos de negócio como o foco central dos esforços da organização com o viés estratégico de identificar e atender plenamente as necessidades dos clientes e demais partes interessadas. Apesar da reengenharia estar caindo em desuso, o foco nos processos de negócio se mantém importante.

\subsection{Gestão por processos}

A gestão por processos começou a ganhar força quando se percebeu as limitações das empresas que atuam de maneira exclusivamente funcional. Os modelos de gestão funcionais possuem algumas lacunas. Uma organização funcional cria um efeito de silo dentro da organização (JESTON; NELIS, 2008), enquanto que uma organização voltada para processos gira em torno principalmente dos processos de negócio e da visão focada no cliente. Esses mesmos autores colocam que processos são o link entre a organização e seus clientes, parceiros, canais de distribuição, produtos e serviços, pessoas e outros stakeholders.

Vários autores trazem uma definição para o conceito de Business Process Management (BPM). Goldkuhl e Lind (2008) resumem de forma apropriada a origem do BPM. Para os autores, BPM é uma visão da organização onde há uma ênfase no trabalho horizontal em detrimento da divisão vertical de trabalho e sua origem remonta nas técnicas de gestão pela qualidade total (GQT) e na reengenharia de processos. Ainda nessa linha, para Hung (2006), BPM é uma filosofia de gerenciamento integrado e um conjunto de práticas que incluem mudanças radicais nos processos, melhoria contínua, ênfase na satisfação do cliente e no envolvimento dos empregados

Segundo Barbará (2006), a gestão por processos pode ser entendida como um modelo de gestão organizacional, orientado para gerir a organização com foco nos processos. Assim, a organização, ao adotar um sistema deste tipo, deverá, inicialmente, pensar em sua melhor forma de fazer negócios.

Segundo Zairi (1997), BPM é uma abordagem estruturada que é dependente de elementos estratégicos, elementos operacionais, ferramentas e técnicas modernas, envolvimento das pessoas e, principalmente o foco horizontal que cumprirá as exigências dos consumidores de uma forma otimizada e satisfatória.

UNICAMP (2003 apud BARBARÁ, 2006) trata a Gestão por Processos como o 
[...] enfoque administrativo aplicado por uma organização que busca a otimização e melhoria da cadeia de processos, desenvolvida para atender necessidades e expectativas das partes interessadas, assegurando o melhor desempenho possível do sistema integrado a partir da mínima utilização de recursos e do máximo índice de acerto.

Alguns autores associam diretamente a um modelo para melhorar o desempenho e atingir os objetivos da organização como um todo. Jeston e Nelis (2008) definem BPM como o atingimento dos objetivos de uma organização através da melhoria, gerenciamento e controle dos processos de negócio essenciais. Para Harmon (2010), BPM é a coordenação de um número diferente de esforços organizacionais para melhorar o desempenho global e o sucesso das organizações. Já Burlton (2001) define Gestão por Processos de Negócios, como um processo que assegura a melhoria contínua no desempenho da organização.

\section{Metodologia}

\subsection{Natureza, abordagem e método de pesquisa}

Sob o ponto de vista da sua natureza, as pesquisas podem ser classificadas como pura ou aplicada. Este estudo pode ser classificado como pesquisa aplicada, pois pretende contribuir de maneira prática para solucionar um problema concreto - a dificuldade de identificar as percepções de profissionais envolvidos na implementação da gestão por processos acerca de aspectos envolvidos em sua aplicação.

Com relação à abordagem, as pesquisas podem ser classificadas como quantitativas ou qualitativas. Esta pesquisa tem uma abordagem qualitativa, pois a interpretação dos fenômenos é imprescindível para o alcance dos objetivos propostos. Além disso, não há como traduzir em aspectos numéricos as principais questões que este estudo pretender responder.

As pesquisas também podem ser classificadas, quanto aos seus objetivos, em descritiva, explicativa ou exploratória. Este estudo pode ser classificado como exploratória, uma vez que busca conhecer melhor o tema abordado.

As pesquisas também são classificadas de acordo com os procedimentos técnicos utilizados. O método utilizado no presente estudo é o estudo de caso, forma geralmente assumida na pesquisa exploratória.

O Quadro 2 apresenta um resumo da metodologia aplicada no estudo.

Quadro 2 - Síntese da metodologia de pesquisa

\begin{tabular}{|c|c|}
\hline Atributo & Método \\
\hline Natureza da Pesquisa & Pesquisa Aplicada \\
\hline Abordagem da Pesquisa & Pesquisa Qualitativa \\
\hline Objetivos da Pesquisa & Pesquisa Exploratória \\
\hline Método da Pesquisa & Estudo de Caso \\
\hline
\end{tabular}

Fonte: Autoria própria (2013)

\subsection{Definição da amostra e delineamento do estudo de caso}


Uma vez definidas as questões a serem tratadas na pesquisa, foi utilizado o método de estudo de caso para obter as informações desejadas.

Todas as etapas do estudo de caso aparecem descritas na Figura 1.

Figura 1 - Delineamento do estudo de caso

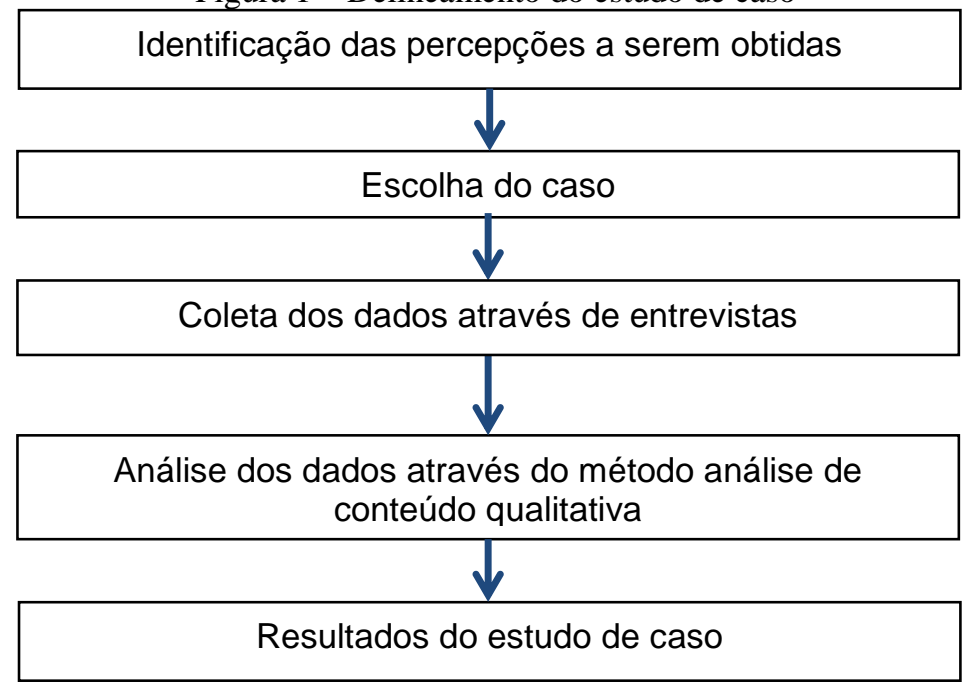

Fonte: Autoria própria (2013)

Esse método pode englobar estudo de múltiplos casos, mas no contexto deste trabalho, foi utilizado o estudo de caso único. Essa opção se deu por ele representar um estudo de caso típico, em que a situação analisada representa uma forma comum de implantação da gestão por processos em uma organização.

O modelo concebido foi aplicado em uma área de negócio de uma empresa do ramo de energia. O fator que contribuiu para escolha do caso foi que a área em questão passa por uma transformação em seu modelo de gestão, migrando de uma visão estritamente funcional para uma visão balanceada entre resultados e processos.

\subsection{Coleta e tratamento dos dados}

Na visão de Marconi e Lakatos (2001), os dados podem ser classificados, segundo sua procedência, em primários ou secundários. Este estudo se utiliza de dados primários, gerados nas entrevistas.

A coleta de dados, ou evidências como denominado por Yin (2005), se deu por meio de entrevistas de forma espontânea, em que tanto se indaga os respondentes-chave sobre fatos, como se pede a opinião ou interpretação deles sobre determinados assunto. O pesquisador optou por esse tipo de entrevista, pois muitos dos envolvidos contribuíram com seus pontos de vista de maneira informal.

A entrevista foi realizada com oito envolvidos na implantação da gestão por processos na área do estudo de caso. Buscou-se analisar as vantagens, desvantagens, facilitadores, dificultadores 
e os pontos mais importantes referentes à aplicação deste modelo na área. $\mathrm{O}$ roteiro completo da entrevista segue abaixo:

a) Quais são as vantagens e pontos positivos da gestão por processos?

b) Quais são as desvantagens e pontos negativos do modelo aplicado?

c) O que facilitou a implantação do modelo?

d) O que dificultou a implantação do modelo?

e) Quais são os fatores críticos de sucesso para implantação do modelo?

Para tratamento dos dados, utilizou-se o método de análise de conteúdo qualitativa. Esse método visa identificar o que está sendo dito a respeito de determinado tema. Essa técnica apresentada por Mayring (2000) possibilita a sistematização e interpretação dos dados a partir da construção de categorias principais que orientam a compreensão do objeto pesquisado. As categorias são obtidas de modelos teóricos, ou seja, uma teoria pré-existente serve de base para a definição dos grupos.

Mayring (2000) propõe três formas de análise de conteúdo qualitativa: sumarização, explicação e estruturação. Neste estudo, foi aplicada a sumarização, cujo objetivo da análise é reduzir o material de tal forma que sobrem apenas os conteúdos essenciais.

Esse método foi utilizado para analisar os dados obtidos principalmente nas entrevistas, que buscaram informações sobre os pontos de vistas dos envolvidos na implantação da gestão por processos na área. Na análise dos dados, buscou-se identificar as percepções mais comuns para cada pergunta feita. Categorizou-se, então, da maneira apresentada no Quadro 3.

Quadro 3 - Categorização das respostas das entrevistas

\begin{tabular}{|c|c|}
\hline Número de entrevistados que citou a observação & Categoria \\
\hline 4 ou mais entrevistados & Percepção muito relevante \\
\hline 2 ou 3 entrevistados & Percepção relevante \\
\hline Apenas 1 entrevistado & Percepção isolada \\
\hline
\end{tabular}

Fonte: Autoria própria (2013)

Além disso, foram mencionadas também as opiniões complementares (ou até confilitantes) que um ou outro entrevistado apontou, mas que não foram levantadas pela grande maioria dos envolvidos.

\section{Estudo de caso}

Esta seção tem por objetivo apresentar o caso em que o modelo conceitual foi testado. Por questões de confidencialidade, o nome da empresa não pôde ser revelado. Desta maneira, neste capítulo são abordadas algumas informações genéricas da organização de forma a caracterizá-la. 
As entrevistas foram realizadas em uma área de uma empresa integrada de energia. A empresa está presente em todos os continentes e é considerada uma das dez maiores do mundo no seu ramo. Ela atua em praticamente todos os elos da cadeia, desde a descoberta do petróleo e gás natural até a comercialização dos produtos finais, trabalhando também com diversas fontes alternativas de energia como biocombustíveis, eólica, entre outras. Assim como a maioria das grandes corporações do setor, a empresa possui atividades tanto em terra como no mar. Alguns números da empresa ao final do exercício de 2010 seguem abaixo:

- Valor de mercado acima de US\$ 100 bilhões;

- Receita operacional e lucro operacional superiores a US\$ 120 bilhões e a US\$ 20 bilhões respectivamente;

- Investimentos acima de US\$ 15 bilhões;

- Produção de petróleo e gás maior do que 2 milhões de barris de óleo equivalente por dia;

- Venda de Derivados acima de 3 milhões de barris por dia;

- Reservas Provadas superando a marca de 8 bilhões de barris de óleo equivalente;

- Número de funcionários superior a 50 mil.

O modelo foi aplicado em uma das maiores áreas de negócio da empresa, responsável por boa parte dos resultados econômicos e operacionais e dos investimentos da organização para os próximos anos, de acordo com seu plano de negócios divulgado recentemente.

\section{Análise de resultados}

Esta seção traz as percepções dos entrevistados acerca dos pontos sinalizados no subtópico 3.3. Entre setembro de 2011 e janeiro de 2012 foram realizadas oito entrevistas com integrantes da força de trabalho que participaram da implantação da gestão por processos na área.

A análise dos dados foi feita através de categorização, conforme apresentado no Quadro 3 do capítulo de metodologia. Se quatro ou mais entrevistados citaram a mesma resposta, esta foi categorizada como "percepção muito relevante". Se dois ou três respondentes convergiram para uma mesma observação, esta foi classificada como "percepção relevante" e caso uma resposta tenha sido lembrada por apenas uma pessoa, ela foi considerada como "percepção isolada".

Os subtópicos abaixo apresentam os resultados de cada pergunta da entrevista.

\subsection{Vantagens e pontos positivos da gestão por processos}

Esta pergunta apresentou maior número de respostas convergentes. Isso demonstra que os envolvidos no trabalho internalizaram os conceitos da gestão por processos. 
Como percepções muito relevantes, foram destacados sete pontos como vantagens e pontos positivos da gestão por processos. Quatro ou mais respondentes indicaram que esse modelo de gestão:

- Identifica claramente papéis e responsabilidades no processo, reduzindo o desperdício e as duplicidades. Isso facilita a ação, pois quando algo estiver aquém do desejado, sabe-se quem deve agir para solucionar o problema;

- Explicita as interfaces e integração entre os processos;

- Promove cultura de melhoria contínua e isso se traduz em aumento de produtividade e em processos eficientes e eficazes;

- Promove a gestão pró-ativa, pois ao atuar nos processos, que é onde se tem gerência, se consegue reduzir ou eliminar o impacto dos problemas antes que eles se reflitam nos resultados;

- Proporciona a visão sistêmica, permitindo o melhor para a organização como um todo e não para cada processo ou cada área individualmente;

- Facilita a identificação da causa raiz do problema, permitindo atuação para eliminá-la e para evitar que volte a ocorrer novamente. Um entrevistado colocou que a gestão por processos resolve o problema de maneira definitiva no tempo correto;

- Explicita os processos, garantindo uniformização de entendimento por parte de todos os envolvidos. Um entrevistado sinalizou que algumas das vantagens são explicitar conhecimento tácito, facilitar treinamento das pessoas e ampliar o conhecimento.

Diversos pontos foram citados três ou duas vezes, sendo classificados, portanto, como percepções relevantes. Segundo os entrevistados, a gestão por processos:

- Traz resultados sustentados no longo prazo, fruto do fortalecimento dos processos;

- Identifica a relação de causa e efeito;

- Proporciona tomada de decisão mais eficaz;

- Facilita o gestor da organização na simplificação do trabalho e permite que as pessoas trabalhem menos, pois proporciona uma gestão melhor das atividades;

- Permite que as pessoas enxerguem a contribuição de suas atividades no resultado da organização.

- Permite um importante conflito dos diferentes pontos de vista (processos x estrutura organizacional), em prol da organização, por conta da visão matricial.

Como principal percepção isolada foi mencionado que a gestão por processos traz objetividade, foco e mostra a razão de ser da empresa, o que ela faz e como faz. Outras observações citadas apenas uma vez foram que a gestão por processos identifica problemas com relação à 
estrutura organizacional e também identifica atividades que não estão agregando valor para organização com um todo.

O Quadro 4 resume as percepções dos entrevistados a respeito das vantagens e pontos positivos da gestão por processos.

Quadro 4 - Resumo das percepções a respeito das vantagens e dos pontos positivos da gestão por processos

\begin{tabular}{|c|c|}
\hline Categoria & Percepção \\
\hline Muito Relevante & Identifica claramente papéis e responsabilidades no processo \\
\hline Muito Relevante & Explicita as interfaces e a integração entre os processos. \\
\hline Muito Relevante & Promove a cultura de melhoria contínua \\
\hline Muito Relevante & Promove a gestão pró-ativa \\
\hline Muito Relevante & Proporciona a visão sistêmica \\
\hline Muito Relevante & Facilita a identificação da causa raiz do problema \\
\hline Muito Relevante & Eraz resultados sustentados no longo prazo \\
\hline Relevante & Identifica a relação de causa e efeito \\
\hline Relevante & Proporciona tomada de decisão mais eficaz \\
\hline Relevante & Facilita o gestor da organização na simplificação do trabalho \\
\hline Relevante & Permite que as pessoas enxerguem a contribuição de suas atividades no resultado da \\
\hline organização
\end{tabular}

Fonte: Autoria própria (2013)

\subsection{Desvantagens e pontos negativos da gestão por processos}

Essa questão apresentou poucas respostas. Alguns dos entrevistados simplesmente não enumeraram pontos negativos da gestão por processos. Outros citaram pontos que foram enquadradas como dificuldades para implementação do modelo e não como desvantagens.

Por conta das poucas observações, neste tópico também não houve percepções que pudessem ser classificadas como muito relevantes. Apenas uma foi considerada como relevante. $\mathrm{O}$ fato da gestão por processos vir de cima para foi levantado como principal ponto negativo. Isso porque algumas questões precisaram ser revistas quando a implementação chegou às unidades e, por isso, enfrentou resistência por parte delas.

Foi citado, isoladamente, o fato de esse modelo ser altamente dependente de patrocínio da alta administração. Também foi lembrado, como desvantagem, o fato de que a gestão por processos exigir certo grau de abstração das pessoas que trabalham mais com atividades operacionais ou técnicas, o que gera certa impaciência.

A visão dos entrevistados sobre as desvantagens e pontos negativos do modelo de gestão segue no Quadro 5. 
Quadro 5 - Resumo das percepções a respeito das desvantagens e dos pontos negativos da gestão por processos

\begin{tabular}{|c|c|}
\hline Categoria & Percepção \\
\hline Relevante & Implementação de maneira top-down \\
\hline Isolada & Altamente dependente de patrocínio da alta administração \\
\hline Isolada & $\begin{array}{c}\text { Necessidade de certo grau de abstração das pessoas que trabalham mais com atividades } \\
\text { operacionais ou técnicas }\end{array}$ \\
\hline
\end{tabular}

Fonte: Autoria própria (2013)

\subsection{Facilitadores para implantação da gestão por processos}

No questionamento sobre os fatores que facilitaram a aplicação do modelo na área estudada, houve grande convergência nas respostas e apenas uma percepção isolada.

Três percepções puderam ser consideradas como muito relevantes. Foi quase unanimidade a questão do forte patrocínio, principalmente do diretor da área (figura máxima da cadeia de comando) e do gestor de dois macroprocessos de negócio. Também com muitas indicações aparece o conhecimento e experiência avançada no tema processos da equipe que conduziu os trabalhos. De acordo com um entrevistado, isso permitiu boas discussões técnicas. Ainda com relação à equipe, o fato de ela ter sido destacada exclusivamente para implantar a gestão por processos foi colocado por quatro respondentes.

Foram citadas por três entrevistados que na companhia existem pessoas que já trabalharam com GQT no passado e que algumas pessoas formadoras de opinião compraram a ideia. A explicitação dos processos faz com que as pessoas passem a se enxergar na cadeia e consequentemente se tornem mais motivadas a atuarem no modelo.

Ainda na classe relevante, foi lembrado que uma estrutura organizacional que possui uma área corporativa com a responsabilidade bem clara de atuar como gestora do processo facilita aplicação da gestão por processos.

Isoladamente, foi colocado que o perfil da força de trabalho contribui para a implementação desse modelo de gestão.

Os resultados da percepção dos entrevistados sobre os facilitadores para implantação do modelo seguem no Quadro 6.

Quadro 6 - Resumo das percepções com relação aos facilitadores para implantação da gestão por processos

\begin{tabular}{|c|c|}
\hline Categoria & Percepção \\
\hline Muito Relevante & Forte patrocínio \\
\hline Muito Relevante & $\begin{array}{l}\text { Equipe com conhecimento e experiência avançada no tema processos para conduzir } \\
\text { os trabalhos }\end{array}$ \\
\hline Muito Relevante & Equipe com dedicação exclusiva para conduzir os trabalhos \\
\hline Relevante & A existência de pessoas na organização que já tenha trabalhado com GQT \\
\hline Relevante & Pessoas formadoras de opinião que comprem a ideia \\
\hline Relevante & $\begin{array}{l}\text { Estrutura organizacional que possua uma área corporativa atuando como gestora de } \\
\text { processo }\end{array}$ \\
\hline Isolada & Perfil da força de trabalho \\
\hline
\end{tabular}

Fonte: Autoria própria (2013)

\subsection{Dificultadores para implantação da gestão por processos}


O maior dificultador para implantação da gestão por processos, levantado por cinco entrevistados, foi a resistência das pessoas, algumas por não entenderem os ganhos da gestão por processos e outras pela própria natureza de restrição a tudo que é novo.

A resistência das pessoas foi citada pelos respondentes de formas diferentes. Para um entrevistado, essa resistência gerou dificuldade inicial de envolvimento das pessoas, apesar do patrocínio. O mesmo entrevistado citou que há um receio nas pessoas de que isso seja mais um modismo.

A questão do patrocínio foi mencionada por quatro entrevistados como um dificultador. Ela foi lembrada de duas formas:

- O forte patrocínio gerava uma cobrança muito forte. Isso fazia com que se avançasse muito rápido em determinados momentos, sem que houvesse maturidade suficiente para tal;

- Os membros da alta gestão da área achavam que dominavam o tema processos, mas na verdade não tinham o conhecimento mais atual do assunto. Isso fez com que, em algumas ocasiões, os trabalhos fossem direcionados para caminhos diferentes do que as boas práticas recomendam. Além disso, como queriam mostrar que estavam patrocinando a gestão por processos, eles interferiam nas definições e em alguns casos modificavam posteriormente decisões que já haviam sido tomadas. Um entrevistado colocou essa questão da seguinte forma: "Em alguns casos, os gestores de mais alto nível interferiram tardiamente quando tiveram oportunidade de interferir durante o andamento das atividades. E isso trouxe certo desgaste no final”.

$\mathrm{Na}$ categoria relevante, foi colocada a falta de visão de processo. A visão da estrutura organizacional é bastante forte nas empresas, ou seja, ainda se tem baixa maturidade no tema "processos".

Uma questão levantada por dois entrevistados foi que a implantação do modelo mexe com a estrutura de poder da organização e quem perde poder normalmente dificulta o avanço dos trabalhos.

Dois respondentes citaram a falta de visão sistêmica, seja por parte das unidades organizacionais, seja por parte dos técnicos que participaram mais ativamente dos trabalhos.

A cultura de padronização predominante na empresa, voltada para a visão funcional, onde se mapeia o processo da gerência e se gera padrões também foi considerada como dificultador por dois entrevistados.

Como percepções isoladas das principais dificuldades aparecem:

- Durante a implantação, todos querem se enxergar de forma explícita e nem sempre isso é possível; 
- A etapa de planejamento não foi validada pelos envolvidos e isso gerou alguns problemas durante a implantação;

- Durante a implantação propriamente dita, a necessidade de validar com todos os envolvidos, que é uma boa prática pregada na gestão por processos, foi lembrada por um entrevistado como um dificultador, pois torna o trabalho cansativo e mais demorado;

- A empresa não evoluiu na área de gestão como evoluiu na área técnica e isso dificulta a implantação de uma gestão por processos;

- Conciliar as visões de estrutura, de função técnica e de processos que em casos raros convergem em uma única visão.

As principais dificuldades levantadas pelos envolvidos para a implantação do modelo estão representadas no Quadro 7.

Quadro 7 - Resumo das percepções com relação aos dificultadores para implantação da gestão por processos

\begin{tabular}{|c|c|}
\hline Categoria & Percepção \\
\hline Muito Relevante & A resistência das pessoas da organização, especialmente dos gestores de processo \\
\hline Muito Relevante & $\begin{array}{c}\text { O forte patrocínio, se não for bem aproveitado, faz com que se avance muito } \\
\text { rapidamente em determinados momentos }\end{array}$ \\
\hline Muito Relevante & $\begin{array}{l}\text { Os membros da alta gestão da área não possuírem o conhecimento mais atual do } \\
\text { assunto }\end{array}$ \\
\hline Relevante & Falta de visão de processos \\
\hline Relevante & A implantação do modelo mexe com a estrutura de poder da organização \\
\hline Relevante & Falta de visão sistêmica \\
\hline Relevante & A cultura de padronização voltada para a visão funcional \\
\hline Isolada & Todos querem se enxergar de forma explícita e nem sempre isso é possível \\
\hline Isolada & A etapa de planejamento não envolver os diversos participantes \\
\hline Isolada & $\begin{array}{c}\text { A validação com todos os envolvidos durante a fase de implantação torna o trabalho } \\
\text { cansativo e mais demorado }\end{array}$ \\
\hline Isolada & A área de gestão das empresas não evoluída \\
\hline Isolada & Dificuldade de conciliar as visões de estrutura, de função técnica e de processos \\
\hline
\end{tabular}

Fonte: Autoria própria (2013)

\subsection{Fatores críticos de sucesso na implantação da gestão por processos}

Esta foi a pergunta que apresentou maior número de respostas, mas poucas foram repetidas muitas vezes pelos entrevistados.

O fator crítico de sucesso mais citado, com quatro referências, foi o comprometimento das pessoas e para tanto é fundamental que elas comprem a ideia.

Foram considerados fatores críticos de sucesso por dois ou três entrevistados as seguintes percepções:

- Patrocínio e envolvimento de todos os gestores do nível hierárquico mais alto;

- Equipe com experiência e capacitação no tema dedicado exclusivamente à implantação da gestão por processos. Ainda com relação à equipe, um entrevistado colocou que ela deve ter pulso firme e ao mesmo tempo ser flexível; 
- A comunicação também é crítica para o sucesso do modelo. Todos os envolvidos devem saber os ganhos esperados com a gestão por processos, as etapas da implantação e o que cada um deve fazer no dia-a-dia do trabalho para contribuir com o modelo de gestão proposto;

- Perseverança, uma vez que a resistência é grande e as mudanças de escopo são constantes;

- Cadeia de valor bem definida e compartilhada por todos. Alinhamento entre a estratégia e os processos, principalmente os de mais alto nível;

- Papéis e responsabilidades bem definidos e entendidos por todos os envolvidos, com destaque para os gestores de processos;

- Identificação de pessoas chave para participar das discussões;

- Disciplina para fazer com que as etapas sejam cumpridas;

- Incorporação das práticas de gestão de processo na rotina de trabalho de todos;

- A estrutura da organização (pessoas, sistemas, capacitação) tem que ser preparada para implementação do modelo;

- Tempo dedicado para o assunto, principalmente por parte dos gestores de processos.

Diversos fatores críticos foram mencionados apenas uma vez, como percepção isolada:

- Definição dos gestores e o empenho individual de cada um para cumprir seu papel. Ficou claro que, nos processos em que o gestor atuava de forma mais ativa o trabalhou fluiu melhor, ficou mais robusto e os resultados foram melhores e mais rápidos;

- Articulação com as áreas envolvidas no trabalho;

- Fazer com que o trabalho permeie toda organização, chegando principalmente até a frente operacional;

- Apresentar casos de sucesso para demonstrar a utilidade do modelo;

- Adaptação do modelo à realidade;

- Uniformização de conceitos / glossário relacionado a processos;

- Conciliar as três diferentes visões - estrutura organizacional, processos e função técnica - e mediar os conflitos entre elas.

Os fatores críticos de sucesso apontados pelos entrevistados aparecem listados no Quadro 8.

Quadro 8 - Resumo das percepções com relação aos fatores críticos de sucessos para implantação da gestão por

\begin{tabular}{|c|c|}
\multicolumn{2}{c|}{ processos } \\
\hline Categoria & Percepção \\
\hline Muito Relevante & Comprometimento das pessoas \\
\hline Relevante & Patrocínio e envolvimento de todos os gestores do nível hierárquico mais alto \\
\hline Relevante & $\begin{array}{c}\text { Equipe com experiência e capacitação no tema dedicada exclusivamente à } \\
\text { implantação da gestão por processos }\end{array}$ \\
\hline Relevante & Comunicação \\
\hline Relevante & Perseverança \\
\hline Relevante & Cadeia de valor bem definida e compartilhada por todos \\
\hline
\end{tabular}




\begin{tabular}{|c|c|}
\hline Categoria & Percepção \\
\hline Relevante & Alinhamento entre a estratégia e os processos, principalmente os de mais alto nível \\
\hline Relevante & Papéis e responsabilidades bem definidos e entendidos por todos os envolvidos \\
\hline Relevante & Identificação de pessoas chave para participar das discussões nos grupos \\
\hline Relevante & Disciplina para fazer com que as etapas sejam cumpridas \\
\hline Relevante & Incorporação das práticas de gestão de processo na rotina de trabalho de todos \\
\hline Relevante & A estrutura da organização (pessoas, sistemas, capacitação) tem que ser preparada \\
para implementação do modelo
\end{tabular}

Fonte: Autoria própria (2013)

Muitos dos fatores críticos indicados pelos entrevistados já haviam sido apontados como dificultadores ou facilitadores da implantação do modelo.

\section{Conclusões}

Esta seção finaliza o estudo a respeito da percepção da implantação da gestão por processos em uma organização. Ele se divide em duas partes. Inicialmente, são apresentadas as conclusões relativas ao objetivo do trabalho. Em seguida, na seção de considerações finais, são trazidas as principais conclusões obtidas neste estudo.

\subsection{Objetivo da pesquisa e resultados obtidos}

Seguindo a lógica do capítulo da introdução, primeiramente foi feita a contextualização e em seguida levantada a situação problema, que deu origem ao objetivo geral para esta pesquisa. O objetivo definido foi identificar as percepções de profissionais envolvidos na implementação da gestão por processos acerca de aspectos envolvidos em sua aplicação.

Pode-se considerar que o objetivo do estudo foi atingido, uma vez que as entrevistas conseguiram captar todos os aspectos que se desejava para fazer análise de questões referentes a implantação da gestão por processos em uma organização.

Os entrevistados listaram uma série de vantagens da gestão por processos, sendo que algumas delas foram citadas muitas vezes. No âmbito geral, essa foi a questão que mais apresentou respostas categorizadas como muito relevantes. Pode-se concluir, portanto, que os conceitos relacionados ao tema foram absorvidos pelas pessoas que trabalharam na implantação do modelo. A percepção dos envolvidos sobre esse ponto direcionou para o conhecimento dos processos como um todo, com sua explicitação, definição de papéis e responsabilidades, integração, interfaces, visão 
sistêmica. Também foram destacadas a atuação direta no problema e a gestão pró-ativa por conta disso, além da cultura de melhoria contínua.

Poucas observações foram feitas a respeito dos pontos negativos do modelo. Apenas uma desvantagem foi levantada por mais de um entrevistado e mesmo assim, por somente duas pessoas: o fato de o modelo ter sido implantando de maneira top-down fez com que houvesse certa resistência nessas unidades.

Os facilitadores mais citados estão relacionados à equipe que deve conduzir os trabalhos: tanto a capacitação no assunto, quanto a dedicação exclusiva para coordenar a aplicação do modelo foram lembradas por quatro entrevistados. Além disso, o forte patrocínio foi quase unanimidade entre os respondentes.

Com relação às dificultadores, a alta administração foi mencionada tanto na carência de conhecimento sobre o tema, como na forte pressão exercida. A resistência das pessoas da organização, principalmente dos gestores, também foi ressaltada diversas vezes como um dificultador.

Apenas o comprometimento das pessoas foi lembrado por quatro entrevistados como fator crítico de sucesso na implantação do modelo. Essa pergunta trouxe novamente alguns pontos já mencionados anteriormente como facilitadores ou dificultadores, ou seja, algumas questões que deram certo ou que atrapalharam a aplicação foram consideradas críticas, como o patrocínio, uma equipe capacitada e exclusiva para coordenar os trabalhos, o convencimento das pessoas da organização, entre outros.

As percepções dos entrevistados categorizadas como muito relevantes aparecem de forma consolidada no Quadro 9.

Quadro 9 - Resumo das percepções muito relevantes dos entrevistados acerca das questões levantadas

\begin{tabular}{|c|c|}
\hline Questão & Percepções muito relevantes \\
\hline \multirow{7}{*}{$\begin{array}{l}\text { Vantagens e pontos positivos da gestão } \\
\text { por processos }\end{array}$} & Identifica claramente papéis e responsabilidades no processo \\
\hline & Explicita as interfaces e a integração entre os processos \\
\hline & Promove a cultura de melhoria contínua \\
\hline & Promove a gestão pró-ativa \\
\hline & Proporciona a visão sistêmica \\
\hline & Facilita a identificação da causa raiz do problema \\
\hline & Explicita os processos \\
\hline $\begin{array}{l}\text { Desvantagens e pontos negativos do } \\
\text { modelo }\end{array}$ & Não houve percepções categorizadas como muito relevantes \\
\hline \multirow{3}{*}{$\begin{array}{l}\text { Facilitadores para implantação do } \\
\text { modelo }\end{array}$} & Forte patrocínio \\
\hline & $\begin{array}{l}\text { Equipe com conhecimento e experiência avançada no tema } \\
\text { processos para conduzir os trabalhos }\end{array}$ \\
\hline & Equipe com dedicação exclusiva para conduzir os trabalhos \\
\hline \multirow{3}{*}{$\begin{array}{l}\text { Dificultadores para implantação do } \\
\text { modelo }\end{array}$} & $\begin{array}{l}\text { A resistência das pessoas da organização, especialmente dos } \\
\text { gestores de processo }\end{array}$ \\
\hline & $\begin{array}{l}\text { O forte patrocínio, se não for bem aproveitado, faz com que se } \\
\text { avance muito rapidamente em determinados momentos }\end{array}$ \\
\hline & $\begin{array}{l}\text { Os membros da alta gestão da área não possuírem o conhecimento } \\
\text { mais atual do assunto }\end{array}$ \\
\hline
\end{tabular}




\begin{tabular}{|c|c|}
\hline Questão & Percepções muito relevantes \\
\hline $\begin{array}{c}\text { Fatores críticos de sucesso na } \\
\text { implantação do modelo }\end{array}$ & Comprometimento das pessoas \\
\hline
\end{tabular}

Fonte: Autoria própria (2013)

\title{
6.2. Considerações finais
}

As organizações têm percebido recentemente que, para alcançar resultados sustentados, é fundamental conhecer e trabalhar nos seus processos. Por isso, cada vez mais buscam evoluir para um novo modelo de gestão, que promove um equilíbrio entre a visão de processos e a visão de resultados. Desta forma, têm crescido o número de organizações que vêm implementando a gestão por processos no seu cotidiano.

No fim da aplicação do modelo, constou-se que a implantação da gestão por processos em uma organização não é simples. Há muita resistência por parte dos diversos atores e é preciso, a todo o momento, costurar procurando atender os principais interesses. Percebeu-se também que é mais oportuno avançar lentamente, mas com todos juntos, do que seguir mais rapidamente com alguns, deixando os demais para trás.

A grande conclusão que se chegou é que a implantação de uma gestão por processos em uma organização é difícil, na maioria dos casos, é demorada, mas é possível e os benefícios que esse modelo propicia, compensa os custos e esforços despendidos.

\begin{abstract}
This study aims to identify the perceptions of professionals involved in a implementation of business process management. For that, it was necessary to study the concepts related to business process management and its history. The methodology considers a research of an applied nature, because it aims to contribute in a practical way to solve a concrete problem. The approach used is qualitative, because the interpretation of the phenomena is essential for achieving the goals. About the goals, this study is classified as exploratory, because it seeks to better understand the topic discussed. And the research method adopted was a case study. Data were collected through interviews spontaneously and analyzed by the method of qualitative content analysis in the form of summarization. The results obtained in this work were the perceptions of the interviews about advantages, positive points, disadvantages, negative points, enablers, difficulties e critical success factors in implementation of business process management.
\end{abstract}

Key-words: business process management; process; total quality.

\section{Referências}

BARBARÁ, S. Gestão por processos: fundamentos, técnicas e modelos de implementação. São Paulo: Qualitymark, 2006.

BURLTON, R. Business process management: profiting from process. Indianapolis: SAMS, 2001.

GOLDKUHL, G.; LIND, M. Coordination and transformation in business processes: towards an integrated view.

Business Process Management Journal, [S.1.], v. 14, no. 6, p. 761-777, 2008. 
HARMON, P. Business process change: a guide for business managers and BPM and six sigma professionals. 2nd. ed. [S.1.]: Elsevier, 2007.

HARMON, P. Process, strategy maps and balanced scorecard. BPTrends, [S.1.], v. 8, no. 5, Mar. 2010.

HUNG, R. Y. Y. Business Process Management as competitive advantage: a review and empirical study. Total Quality Management e Business Excellence, [S.1.], v. 17, no.1, p. 21-40, 2006.

JESTON, J.; NELIS, J. Management by process: a roadmap to sustainable business process management. [S.1.]: Elsevier, 2008.

MARANHÃO, M.; MACIEIRA, M. E. B. O processo nosso de cada dia: modelagem de processos de trabalho. [S.1.: s.n.], 2004.

MARCONI, M. A.; LAKATOS, E. M. Metodologia do trabalho científico: procedimentos básicos, pesquisa bibliográfica, projeto e relatório, publicações e trabalhos científicos. 6. ed. São Paulo: Atlas, 2001.

MAYRING, P. Qualitative content analysis. Forum: qualitative social research, [S.1.], v. 1, no. 2, June 2000.

RUMMLER, G. A.; BRACHE, A. P. Melhores desempenhos das empresas: ferramentas para a melhoria da qualidade e da competitividade. São Paulo: Makron Books, 1994.

SMITH, H.; FINGAR, P. Business process management: the third wave. Florida: Meghan-Kiffer Press, 2003.

SMITH, R. Business process management and balanced scorecard. [S.1.]: Wiley, 2007.

SOUSA NETO, M. V.; MEDEIROS JUNIOR, J. V. Afinal, o que é business process management?: um novo conceito para um novo contexto. Revista Eletrônica de Sistemas de Informação, [S.1.], nov. 2008.

YIN, R. K. Estudo de caso: planejamento e métodos. 3. ed. São Paulo: Bookman Companhia, 2005.

ZAIRI, M. Business process management: a boundaryless approach to modern competitiveness. Business Process Management Journal, [S.1.], v. 3, no. 1, p. 64-80, 1997.

\section{Dados dos autores}

Nome completo: Aziz Khazzah el Warrak

Filiação institucional: Universidade Federal Fluminense

Endereço completo para correspondência: Rua José Peixoto, 291, Centro, São João de Meriti, RJ, CEP: $25520-430$

Telefone: (21) 8871-5074

e-mail: azizkwarrak@yahoo.com.br

Nome completo: José Rodrigues de Farias Filho

Filiação institucional: Universidade Federal Fluminense

Endereço completo para correspondência: Rua Passo da Pátria, 156, sala 330 - São Domingos, Niterói - RJ, CEP: 24210-240.

Telefone: (21) 9944-6270.

e-mail: fariasfilho@gmail.com 
Submetido em: 30/06/2013

Aceito em: 08/10/2014 